\title{
A simple on-line detection system based on fiber-optic sensing for the realtime monitoring of fixed bed adsorption processes of molecularly imprinted polymers
}

\author{
Yiting $\mathrm{Hu}^{\mathrm{a}}$, Turghun Muhammad ${ }^{\mathrm{a}, *}$, Beibei $\mathrm{Wu}^{\mathrm{a}}$, Aixia Wei ${ }^{\mathrm{a}}$, Xiaoxia Yang ${ }^{\mathrm{a}}$, Lingxin Chen ${ }^{\mathrm{b}, \mathrm{c}}$ \\ a College of Chemistry \& Chemical Engineering, Xinjiang University, Xinjiang Key laboratory of Oil and Gas Fine Chemicals, Urumqi 830046, PR China \\ ${ }^{\mathrm{b}}$ CAS Key Laboratory of Coastal Environment Processes and Ecological Remediation, Yantai Institute of Coastal Zone Research, Chinese Academy of Sciences, \\ Yantai, PR China \\ ' School of Chemistry and Chemical Engineering, Yantai University, Yantai 264005, PR China
}

\section{A R T I C L E I N F O}

\section{Article history:}

Received 20 November 2019

Revised 1 April 2020

Accepted 3 April 2020

Available online 27 April 2020

\section{Keywords:}

Fiber-optic sensing

On-line monitoring

Fixed bed adsorption

2,4-dichlorophenoxyacetic acid

Molecularly imprinted polymers

Wastewater treatment

\begin{abstract}
A B S T R A C $T$
Fixed bed adsorption is widely used for separations and purifications of active components in medicine, and for wastewater treatment. At present, fixed bed adsorption breakthrough curve is generally obtained by manual sampling and off-line detection. In this study, we proposed a method for on-line monitoring of fixed bed adsorption process using a self-assembled fiber-optic sensing (FOS) system. The adsorption of 2,4-dichlorophenoxyacetic acid $(2,4-\mathrm{D})$ on the fixed bed packed with molecularly imprinted polymers (MIPs) and non-imprinted polymers (NIPs) were studied. The reproducibility and precision of the system was investigated. The relative standard deviation (RSD) of the system was less than $1.54 \%$, which indicates that the system has a good reproducibility. The effects of initial concentration, flow rate, adsorbent mass and particle size on the breakthrough curves were investigated. Through screening, it was found that adsorption kinetics of the polymer materials fit to Thomas and Yoon-Nelson models. The MIPs showed high binding capacity, good selectivity, fast adsorption rate, indicating a great potential for the treatment of 2,4-D contaminated water. Moreover, this study has identified that the detection method has the advantages of being on-line, realtime, simple, and accurate. The on-line method can facilitate the study of fixed bed adsorption processes and accelerate the understanding of adsorption kinetics.
\end{abstract}

(C) 2020 Elsevier B.V. All rights reserved.

\section{Introduction}

As a highly selective and low-cost herbicide, 2,4dichlorophenoxyacetic acid (2,4-D) is the most frequently utilized to restrain the growth of cocoa, rubber, oil palm and other broad-leaved weeds in agriculture [1-3]. However, it has toxicity and poor degradability. Moreover, it can cause water pollution and endanger human health [4]. The World Health Organization (WHO) suggested that the permissible concentration of 2,4-D should not be over $70 \mu \mathrm{g} / \mathrm{L}$ in drinking water [5]. The highest allowable concentration of 2,4-D in drinking water in China is $30 \mu \mathrm{g} / \mathrm{L}$ [6]. To minimize these risks, 2,4-D needs to be removed from the contaminated waters.

At present, the methods of removing 2,4-D include photocatalytic degradation [7,8], Fenton processes [9,10], advanced oxidation processes [11,12], electrocatalytic degradation [13], electrodial-

\footnotetext{
* Corresponding author.

E-mail address: turghunm@xju.edu.cn (T. Muhammad).
}

ysis membranes [14], and adsorption [15-17]. Among them, the adsorption method is gained popularity due to its low cost and low energy consumption. At present, there are many adsorbents commonly used for adsorbing 2,4-D, such as activated carbon [18], metal-organic framework [19], polymers [20], modified materials [21] and polystyrene beads [22]. Comparing to others, molecularly imprinted polymers (MIPs) are more attractive due to their excellent selectivity, stability and reusability [23]. Although many MIPs were developed aiming at the extraction and removal of contaminants in water, there is almost no any example of practical application in contaminant treatment. There are some excellent MIPs that need to be characterized in the view of practical application. Among them, 2,4-D MIPs are water-compatible, prepared in $\mathrm{H}_{2} \mathrm{O}$ rich solvent, have high binding capacity. From the industrial perspective, the continuous adsorption of fixed bed columns has always been expected [24]. Conventionally fixed-bed adsorption is usually measured by manual sampling to obtain the breakthrough curves. Methods such as HPLC $[1,5]$ and UV-Vis spectrophotometry [17] are usually employed for sampling analysis. Although these methods are widely used, they usually suffer from 


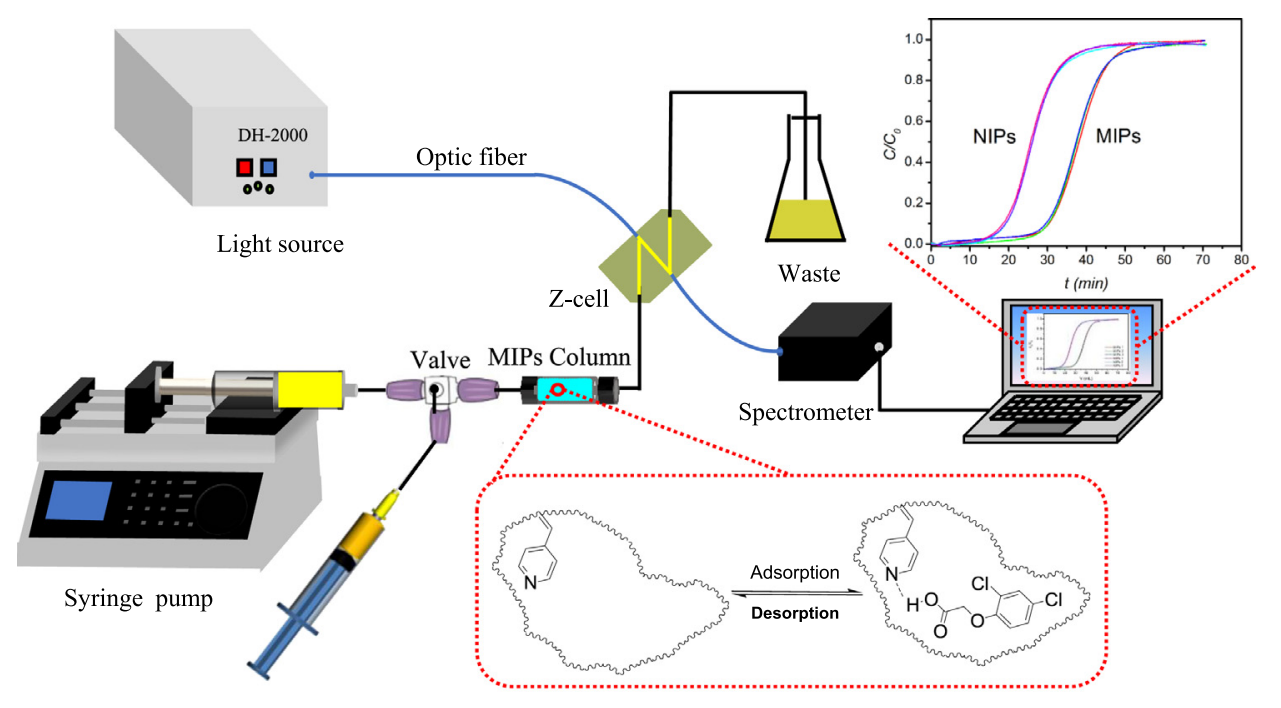

Fig. 1. Schematic illustration of the on-line measurement system of fixed bed adsorption.

time-consuming, labor consumption, limited data as well as errors $[25,26]$. Therefore, it is important to establish an on-line and realtime detection method for fixed bed adsorption.

After a period of development, fiber-optic sensing (FOS) technology has become a prevalent trend due to low cost, high accuracy, on-site and realtime measurement $[27,28]$. Among the fiberoptic spectroscopic method, FOS based on UV Vis absorption has been widely employed because of its low cost, simplicity and high accuracy. For all these merits, it was used widely in instant tablet dissolution [29], environmental monitoring [30], catalytic kinetics [31], and in-situ batch adsorption [32,33]. FOS has advantages over UV detector, such as agility (necessary to capture the fast changing part of the breakthrough curve) and providing whole spectra instantly which is rarely available in traditional UV detectors. Spectra can provide detection of the analyte of interest or multicomponent using chemometrics methods.

A method for on-line detection of fixed bed adsorption process is proposed by applying FOS. The system consists of a syringe pump, a column, a Z-type flow cell, a light source and a fiber-optic spectrometer. MIPs were used as adsorbents for fixed bed adsorption, and adsorption kinetics were studied.

\section{Experimental section}

\subsection{Materials and reagents}

Ethylene glycol dimethacrylate (EGDMA, 97\%), 2,2azoisobutyronitrile (AIBN, 99\%) and 2,4-dichlorophenoxyacetic acid (2,4-D, 97\%) were purchased from Tokyo Chemical Industry Co. Ltd. (Tokyo, Japan). 4-Vinylpyridine (4-VP, 95\%), 2,4dichlorophenylacetic acid (DPAc, 99\%), 4-chlorophenylacetic acid (CPAc, 98\%) and 4-chlorophenoxyacetic acid (CPOAc, 98\%) were supplied by J\&K Chemical (Beijing, China). Methanol, acetonitrile and acetic acid (all analytical reagents) were supplied from Zhiyuan Chemical Reagent (Tianjin, China). High purity water was produced by an apparatus (Chengdu, China). The water samples are from Red Lake in Xinjiang University (Xinjiang, China).

\subsection{Instrumentation}

The configuration of the on-line fiber-optic detection system is depicted in Fig. 1. Deuterium tungsten halogen light source (DH 2000) and fiber-optic spectrophotometer (USB 2000) were connected with an FIA-Z-SMA-Peek Lensed flow cell of $10 \mathrm{~mm}$ of opti- cal path length and $60 \mu \mathrm{L}$ of internal volume by two optical fibers, respectively (all parts from Ocean Optics Dunedin, Florida, USA). The inlet and outlet of Z-type flow cell were connected to waste and the column as a fixed bed through PTFE tubes. The three-way valve (Diba, USA) was placed between the fixed bed and the syringe (Shanghai China) to inject a blank sample for obtaining baseline. A syringe pump (Baoding, China) was used to deliver a solution with a suitable flow rate. FTIR spectra were obtained using $\mathrm{KBr}$ pellets on an EQUINOX 55 (Bruker Optics, Germany). The microscopic morphology of the polymer was characterized by Hitachi SU 8010 scanning electron microscope (Honshu, Japan). The specific surface area was measured using nitrogen adsorption and desorption with the aid of Autosorb-IQ2-MP (Quantachrome Instruments Co. Ltd., USA). Spectral data of sampled solutions were measured by a UV-1800 spectrophotometer (Shimadzu, Japan).

Adaptors for connecting columns with syringe (pump) or optic flow cell with negligible dead volume were explicitly designed (Fig. S1). Each adaptor has one end that fits to a 1/16 internal male nut. The adaptor on the pump side (connected through the valve) was fabricated to precisely fit to the wide end of the column. Fig. S1 shows the geometric size of the adaptor. The setup was also proven to be applicable for HPLC stainless steel columns. Through this setup, adjustable bed volume was achieved by simply cutting the influent end of the plastic column. Furthermore, this is an excellent alternative to expensive commercial glass columns with adjustable bed volumes.

\subsection{Data collection and analysis}

The absorbance of the solution was measured by the on-line fiber-optic detection system. Briefly, the light source was turned on and preheated for a minimum of $30 \mathrm{~min}$, and then Spectra Suite software was activated. After that the Z-type flow cell was filled with the blank solvent, and bubbles in the Z-type flow cell were removed. The light intensity was adjusted to about 27,000 counts at the desired detection wavelength on the software. The integration time and smoothness were set to $20 \mathrm{~ms}$ and 5, respectively, and the dark spectrum and reference spectrum were stored by the application software. Under the above condition, the 2,4-D solutions with different concentrations were injected into Z-type flow cell and absorption spectra were recorded. 


\subsection{Working solutions}

The stock solution of 2,4-D (2000 $\mathrm{mg} / \mathrm{L}$ ) was prepared by accurately weighting of standard sample and completely dissolving in methanol, then stored at $4{ }^{\circ} \mathrm{C}$ in a refrigerator. The working solutions of 2,4-D were prepared by dilution of the stock solution with methanol-water $(1: 9, \mathrm{v} / \mathrm{v})$, and the calibration curves were established by the working solutions. The aliquot working solutions were prepared each time freshly by diluting the stock solution.

\subsection{Synthesis of MIPs and NIPS}

The synthesis procedure of MIPs was adopted from the work reported by Karsten Haupt [20]. In brief, the template 2,4-D $(0.2210 \mathrm{~g}, 1 \mathrm{mmol})$, the functional monomer 4-VP $(0.4205 \mathrm{~g}$, $4 \mathrm{mmol}$ ) were dissolved in $5 \mathrm{~mL}$ mixture of methanol and water $(4: 1, \mathrm{v} / \mathrm{v})$ in a $20 \mathrm{~mL}$ glass bottle. Subsequently, EGDMA (3.9644 g, $20 \mathrm{mmol})$ as a crosslinker and AIBN $(0.05 \mathrm{~g}, 0.31 \mathrm{mmol})$ as initiator were added to the same solution. The pre-polymer solution was ultra-sonicated for $10 \mathrm{~min}$ to homogenize the solution. Then polymerization solution was purged with a stream of nitrogen for 5 min. Then the solution was sealed before being placed in the pre-heated thermostatic water bath, and polymerization was proceeded at $45^{\circ} \mathrm{C}$ for $4 \mathrm{~h}$, followed by $2 \mathrm{~h}$ at $60^{\circ} \mathrm{C}$. After, the hard bulk polymer was ground manually using a mortar and then separated through different meshes. Then, the polymer particles with different sizes (38 54 $\mu \mathrm{m}, 54 \sim 75 \mu \mathrm{m}, 75 \sim 100 \mu \mathrm{m}$ ) were collected. The particles were washed in methanol/acetic acid (7:3) $(2 \times)$, acetonitrile/acetic acid $(9: 1)(2 \times)$, acetonitrile $(1 \times)$, and methanol $(2 \times)$ for $2 \mathrm{~h}$ each time using a Soxhlet extractor and dried in oven at $60{ }^{\circ} \mathrm{C}$. NIPs were prepared following the same procedures but without the addition of 2,4-D.

\subsection{Adsorption and desorption procedures}

The polymer (MIPs and NIPs) adsorbent materials were packed into a column. The column was washed with methanol, and was then activated with methanol-water $(1: 9, \mathrm{v} / \mathrm{v})$ until the absorbance of the effluent below 0.005 . The flow cell was filled with a solvent using a three-way valve. The instrument parameters were adjusted according to Section 2.3. After setting and saving the parameters, and then the 2,4-D solution was flowed through the column by a syringe pump at a constant flow rate. The adsorption solution was detected by the fiber-optic spectrometer when passing through the Z-type flow cell. When the absorbance change of the effluent solution is below 0.002 within $10 \mathrm{~min}$, it is considered that the adsorption reaches saturation. Then, the spectrum software was inactivated, and the data were stored. The same system setup was employed for the subsequent experiment.

After the adsorption process, the desorption solvent was passed through the column at a flow rate of $1.0 \mathrm{~mL} / \mathrm{min}$ and detected by the fiber-optic spectrometer. Due to the high concentration, desorption solutions were collected and diluted for absorbance measurement.

\subsection{Analysis of experimental data}

Adsorption breakthrough curves of 2,4-D were acquired according to the effluent concentration and consumed time. The effluent concentration and the time were determined with the fiber-optic spectrometer. The formula for calculation of effluent volume $V_{\text {eff }}$ is as follows:

$V_{\text {eff }}=Q t_{e}$

Where $Q(\mathrm{~mL} / \mathrm{min})$ is flow rate and $t_{\mathrm{e}}(\mathrm{min})$ is exhaustion time in which effluent passed through of the column. The exhaustion time corresponds to when the effluent concentration is $90 \%$ of the initial concentration. Likewise, the breakthrough time is the time when the effluent concentration is $10 \%$ of initial concentration, expressed as $t_{\mathrm{b}}$. The total mass of the adsorbed 2,4-D, $q_{\text {total }}(\mathrm{mg}$ ) can be achieved using the calculation formula: [34]

$q_{\text {total }}=Q / 1000 \int_{0}^{t_{\text {total }}}\left(C_{0}-C\right) \mathrm{d} t$

where $t_{\text {total }}$ is the total time of adsorption, and $Q$ is flow rate $(\mathrm{mL} / \mathrm{min}), C_{0}$ and $C$ are the initial and effluent concentrations $(\mathrm{mg} / \mathrm{L})$ of $2,4-\mathrm{D}$.

The adsorption capacity $q_{\mathrm{eq}}(\mathrm{mg} / \mathrm{g})$ of $2,4-\mathrm{D}$ at the time of column equilibrium can be calculated according to the following equation:

$q_{\text {eq }}=q_{\text {total }} / m$

where $m(\mathrm{~g})$ is the mass of adsorbent.

\section{Results and discussion}

\subsection{Characterization}

FTIR spectra of the MIPs and NIPs are shown in Fig. 2a. There was no distinct peak around $1636 \mathrm{~cm}^{-1}$, indicating that the polymerization was succeeded. Comparing MIPs and NIPs, the absorption band at $1732 \mathrm{~cm}^{-1}$ can be attributed to $\mathrm{C}=\mathrm{O}$ of cross-linker. The peak at $693 \mathrm{~cm}^{-1}$ was assigned to $\mathrm{C}-\mathrm{Cl}$ stretching. After washing the MIPs, it could be clearly seen that the sharp distinct peaks at $1732 \mathrm{~cm}^{-1}$ and $693 \mathrm{~cm}^{-1}$ of the template molecule were decreased, and that the absorption spectrum is similar to that of NIPs, which indicates the removal of the template molecule.

Fig. 2c and d shows the SEM images of MIPs. The surface is rough and porous indicating that there is a good possibility for 2,4$\mathrm{D}$ to be trapped and adsorbed onto the surface of the pores.

The surface area of the MIPs was measured using the analysis of $\mathrm{N}_{2}$ sorption. The pore size distribution was obtained by the DFT method. The $\mathrm{N}_{2}$ adsorption/desorption isotherm and the pore size distributions are presented in Fig. 2b. The surface area of the MIPs measured by the BET method was $295.37 \mathrm{~m}^{2} / \mathrm{g}$. The average pore diameter and total pore volume were $6.11 \mathrm{~nm}$ and $0.45 \mathrm{~cm}^{3} / \mathrm{g}$, respectively.

\subsection{On-line determination of 2,4-D}

2,4-D solutions in the range of $1.0-160 \mathrm{mg} / \mathrm{L}$ were measured at $283.5 \mathrm{~nm}$ using FOS. The results are shown in the Fig. 3, and the regression equation was $A=0.009 C+0.009\left(R^{2}=0.9993\right)$. The result indicated that on-line measurement of fixed bed adsorption of 2,4-D can be accomplished using the self-made FOS.

\subsection{Repeatability of the on-line measurement}

In this section, the reproducibility of the measurement system was investigated by three parallel experiments. Breakthrough experiments were carried out on MIPs and NIPs columns at the same conditions. As shown in Fig. 4, the three breakthrough curves had almost overlapped each other. According to the adsorption capacity, the RSDs of MIPs and NIPs columns were $0.73 \%$ and $1.54 \%$, respectively. The rate constants were calculated by two models, and the RSDs of MIPs and NIPs of Yoon-Nelson model were $4.49 \%$ and $3.45 \%$, respectively. The RSDs of MIPs and NIPs of Thomas model were $4.53 \%$ and $2.41 \%$, respectively. It can be seen that breakthrough curves obtained by on-line fiber-optic system have no noticeable difference and which indicates that the system has good reproducibility. The fact proves that this method can be well applied to on-line measurement of fixed bed adsorption with the advantages of excellent reproducibility and simple instrumentation. 

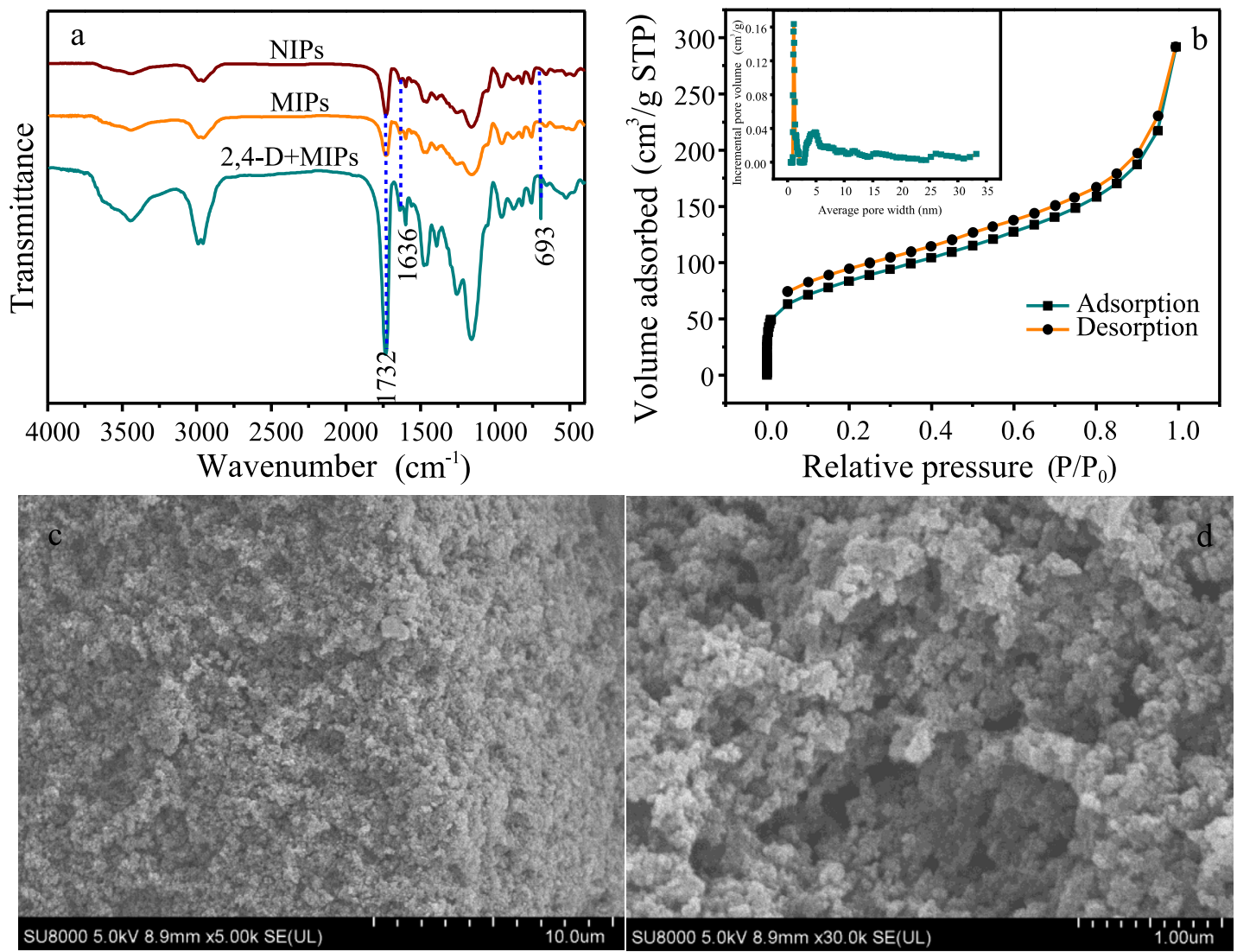

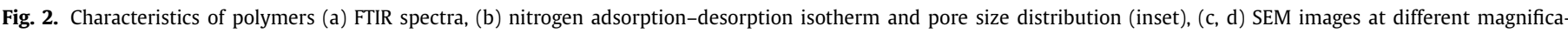
tions.

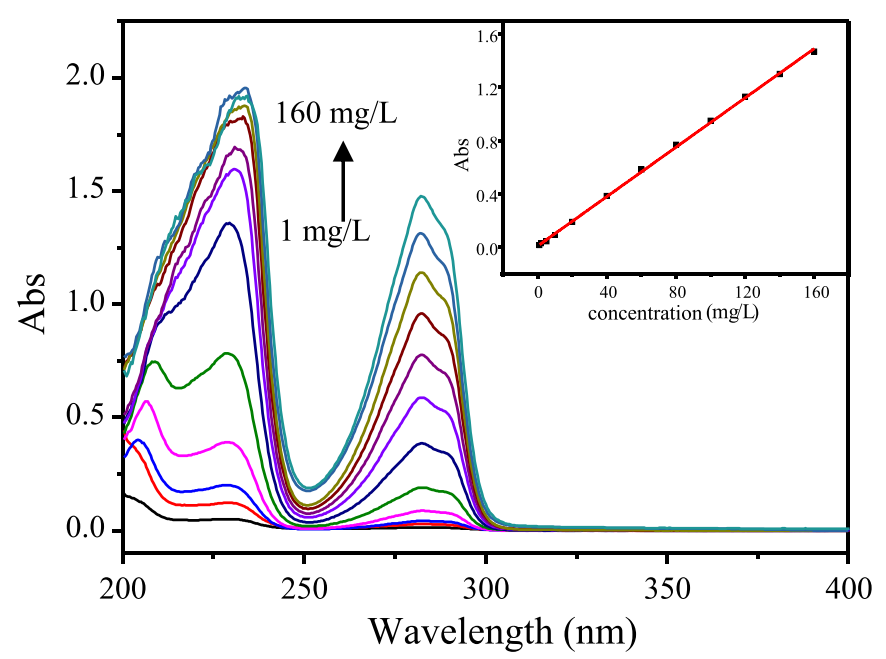

Fig. 3. Absorption spectra and calibration curve of 2,4-D.

\subsection{Comparison with the traditional method}

Under the same conditions, the breakthrough curves were obtained by on-line fiber-optic detection and traditional sampling method, respectively. The concentration of 2, 4-D in the effluent was calculated according to the standard curve (Fig. S2 (A)). As shown in the Fig. 5, the overall trends of breakthrough curves obtained by the two methods are the same. However, the breakthrough curves obtained by the sampling method fell behind that of fiber-optic method. This is due to the FOS method monitoring

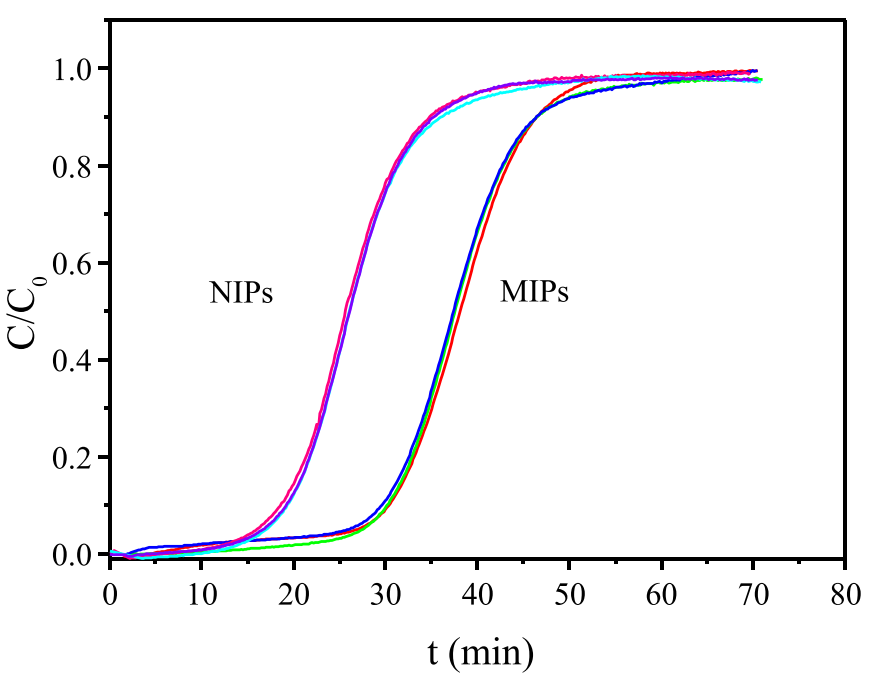

Fig. 4. Breakthrough curves of 2, 4-D on MIPs and NIPs $(n=3)$.

realtime concentration of the flow in the bed, while the sampling method represents averages of past $1 \mathrm{~min}$ sample. It proved that the fiber-optic on-line detection method could be applied to the realtime measurement of the fixed bed adsorption process. The adsorbate concentration increases as the time prolongs. Moreover, the larger the sampling volume is, the lower the measured concentration is than that of actual concentration at the moment. This will cause significant distortion in the traditional method when the adsorption is very fast. Here, simple instrumentation was achieved using common SPE cartridges (can be applied to any column) and 


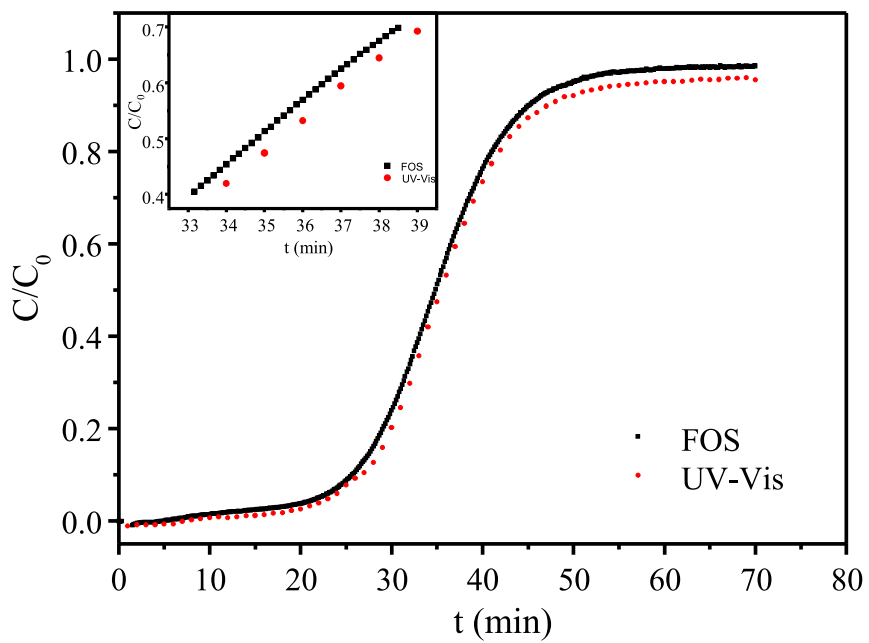

Fig. 5. Comparison of 2, 4-D breakthrough curves obtained by traditional sampling method and on-line method.

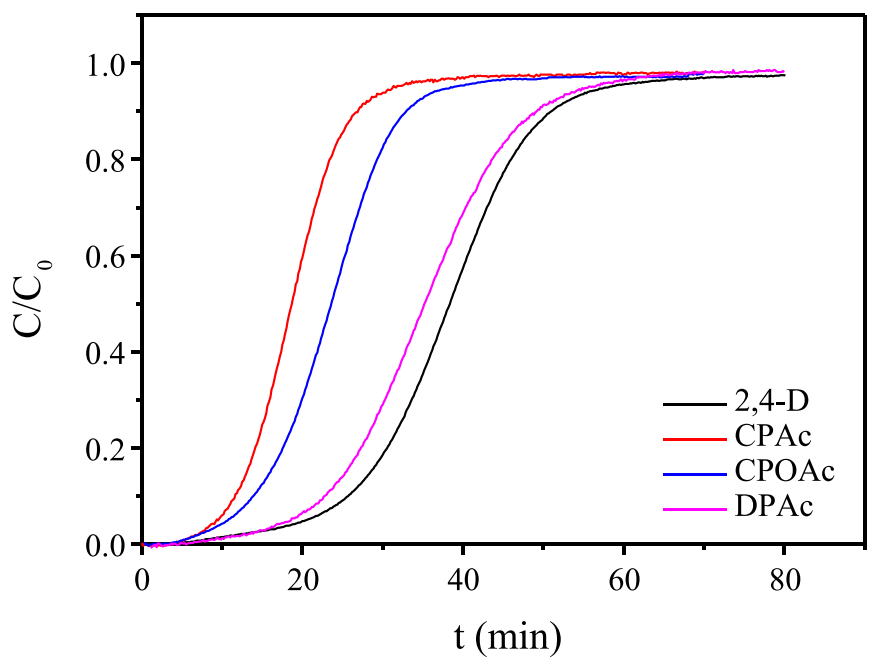

Fig. 6. Breakthrough curves of 2,4-D and its cross-reactants on MIPs.

a three-way valve, without complicated configuration such as the HPLC system.

\subsection{Adsorption selectivity}

The breakthrough curves for 2,4-D analogues are shown in Fig. 6. It is observed that the breakthrough time of $2,4-\mathrm{D}$ is the longest among its analogues. The MIPs binding capacity decrease in the order of 2,4-D, DPAc, CPOAc and CPAc, but the pKa and polarity do not follow this order (Table S1). Actually, this has some degree of agreement with the view, that molecular imprinting is the result of enhanced effect originated from existing interaction of the template with control polymer [35,36]. MIPs have high specificity and selectivity comparable to those of natural receptors, so they have the largest adsorption amount and highest recognition ability to 2,4-D, resulted from a remarkable imprinting effect.

\subsection{2,4-D adsorption in fixed bed}

\subsubsection{Effect of initial 2,4-D concentration}

In order to obtain the effect of 2,4-D initial concentration $\left(C_{0}\right)$ on the MIPs adsorption, the concentrations $\left(C_{0}\right)$ from 80 to $160 \mathrm{mg} / \mathrm{L}$ were investigated. As shown in the breakthrough curves in Fig. 7 (left), the breakthrough time decreased from 31.67 to
Table 1

Parameters obtained to 2.4-D adsorption by MIPs at different conditions.

\begin{tabular}{|c|c|c|c|c|c|c|c|c|}
\hline \multicolumn{4}{|c|}{ Conditions } & \multicolumn{5}{|c|}{ Experimental parameters of breakthrough curve } \\
\hline$\overline{C_{0}}$ & $M$ & $Q$ & $\Phi$ & $t_{\mathrm{b}}$ & $t_{\mathrm{e}}$ & $q_{\text {total }}$ & $q_{\mathrm{eq}}$ & $V_{\text {eff }}$ \\
\hline 160 & 50 & 1.0 & $38-75$ & 30.34 & 46.50 & 6.14 & 122.78 & 46.50 \\
\hline 120 & 50 & 1.0 & $38-75$ & 30.83 & 50.84 & 4.88 & 97.66 & 50.84 \\
\hline 80 & 50 & 1.0 & $38-75$ & 31.67 & 58.83 & 3.67 & 73.42 & 58.83 \\
\hline 160 & 30 & 1.0 & $38-75$ & 13.84 & 31.00 & 3.57 & 118.88 & 31.00 \\
\hline 160 & 40 & 1.0 & $38-75$ & 21.83 & 40.84 & 4.95 & 123.84 & 40.84 \\
\hline 160 & 50 & 0.5 & $38-75$ & 62.30 & 87.14 & 5.96 & 119.22 & 43.57 \\
\hline 160 & 50 & 1.5 & $38-75$ & 19.67 & 31.45 & 6.10 & 121.92 & 47.12 \\
\hline 160 & 50 & 2.0 & $38-75$ & 14.50 & 24.83 & 6.20 & 123.90 & 49.66 \\
\hline 160 & 50 & 1.0 & $38-54$ & 33.33 & 39.67 & 5.91 & 118.27 & 39.67 \\
\hline 160 & 50 & 1.0 & $54-75$ & 29.17 & 44.50 & 5.91 & 118.27 & 44.50 \\
\hline 160 & 50 & 1.0 & $75-100$ & 21.67 & 51.50 & 5.81 & 116.19 & 51.50 \\
\hline
\end{tabular}

Notation: $\mathrm{C}_{0}=$ initial concentration $(\mathrm{mg} / \mathrm{L}), \mathrm{m}=$ weight $(\mathrm{mg}), \mathrm{Q}=$ flow rate $(\mathrm{mL} / \mathrm{min}), \Phi=$ particle size $(\mathrm{mm}), \mathrm{t}_{\mathrm{b}}=$ breakthrough time, $\mathrm{t}_{\mathrm{s}}=$ exhaustion time, $\mathrm{q}_{\text {total }}=$ total mass of 2,4-D adsorbed, $V_{\text {eff }}=$ effluent volume.

$30.34 \mathrm{~min}$, and the saturation time also decreased from 58.83 to $46.51 \mathrm{~min}$ with the increasing of initial concentration from 80 to $160 \mathrm{mg} / \mathrm{L}$. The mass transfer zone of the breakthrough curves becomes narrower and steeper, with the decrease of breakthrough time. This can be explained by the fast saturation of the MIPs fixed bed, when a high number of 2,4-D molecules interact on per unit surface area of the adsorbent $[17,26]$. Besides, it can be discussed that a higher concentration leads to an increase in the mass transfer coefficient or diffusion coefficient [37-39]. With the increase of concentration, the adsorption capacity increased gradually. As the concentration increased from 80 to $160 \mathrm{mg} / \mathrm{L}$, the adsorption capacities increased from 73.42 to $122.78 \mathrm{mg} / \mathrm{g}$ (Table 1).

\subsubsection{Effect of flow rate}

With the flow rate from 0.5 to $2.0 \mathrm{~mL} / \mathrm{min}$, the breakthrough curves were obtained as shown in Fig. 7 (middle). The breakthrough time decreases from 62.30 to $14.50 \mathrm{~min}$ and exhaustion time decreases from 87.14 to $24.83 \mathrm{~min}$ with the increase of flow rate from 0.5 to $2.0 \mathrm{~mL} / \mathrm{min}$, due to deficient contact time [40]. The breakthrough curves were relatively flat, and the mass transfer area was larger at a lower flow rate. With the high flow rate, the breakthrough curve is steeper, which is a results of a higher intraparticle diffusion and smaller mass transfer area [41]. As shown in Table 1 , the adsorption capacity did not significantly improved with the decrease of flow rate, which indicated that MIPs adsorption of 2,4-D is very fast, and that the low flow rate cannot improve column efficiency [41,42].

\subsubsection{Effect of particle sizes}

The effect of particle sizes of MIPs has been investigated in the range 38-54 $\mu \mathrm{m}, 54-75 \mu \mathrm{m}$ and $75-100 \mu \mathrm{m}$. The breakthrough curves are shown in Fig. 7 (right). The figure shows that breakthrough curves of MIPs particles with three different size crossed at the point of $50 \% C / C_{0}$. This indicates that the particle size does not affect adsorption capacity (Table 1 ). The proposed method can accurately represent detailed information of the breakthrough curves. With the increase of particle size, the breakthrough time decreased from 33.36 to $21.67 \mathrm{~min}$ and exhaustion time increased from 39.67 to $51.50 \mathrm{~min}$, as showed in Table 1. In this case the intragranular diffusion serves as the rate limiting step, and the adsorption rate and the ratio of the diffusion coefficient $d_{p}{ }^{2}$ to $D$ is proportional [43]. Therefore, the adsorption rate of large particles was lower than that of small particles. These factors result in the shortest breakthrough time of MIPs with a particle size of 75$100 \mu \mathrm{m}$. The shapes of the breakthrough curves indicate that the longer the particles, the slower the mass transfer. That is probably because the diffusion resistance inside the particle has a dominant 


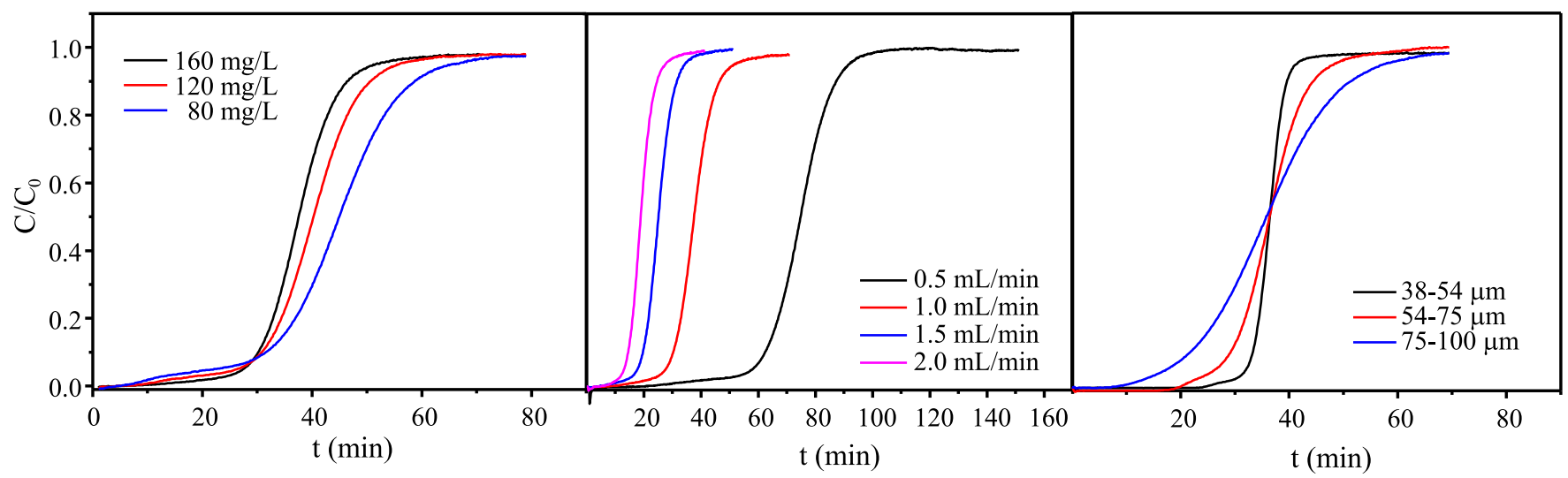

Fig. 7. Breakthrough curves of 2,4-D adsorption on MIPs at different initial 2.4-D concentrations(left), flow rate(middle) and particle size(right).

Table 2

Parameters of Yoon-Nelson, Thomas and Adams-Bohart models for 2,4-D adsorption by MIPs in a fixed-bed adsorption.

\begin{tabular}{|c|c|c|c|c|c|c|c|c|c|c|c|c|}
\hline \multicolumn{4}{|c|}{ Conditions } & \multicolumn{3}{|c|}{ Yoon-Nelson } & \multicolumn{3}{|c|}{ Thomas model } & \multicolumn{3}{|c|}{ Adams-Bohart model } \\
\hline$\overline{C_{0}}$ & $m$ & $Q$ & $\Phi$ & $\overline{k_{\mathrm{YN}}}$ & $\tau$ & $R^{2}$ & $\overline{K_{\mathrm{Th}}}$ & $q_{0}$ & $R^{2}$ & $k_{\mathrm{AB}} \times 10^{3}$ & $N_{0} \times 10^{-4}$ & $R^{2}$ \\
\hline 160 & 50 & 1.0 & $38-75$ & 0.2660 & 38.25 & 0.9991 & 1.6623 & 122.57 & 0.9991 & 1.0783 & 4.1658 & 0.9693 \\
\hline 120 & 50 & 1.0 & $38-75$ & 0.2147 & 40.73 & 0.9970 & 1.8024 & 97.43 & 0.9974 & 1.3138 & 3.2709 & 0.9888 \\
\hline 80 & 50 & 1.0 & $38-75$ & 0.1613 & 44.92 & 0.9963 & 2.0135 & 72.04 & 0.9959 & 1.3760 & 2.4917 & 0.9918 \\
\hline 160 & 30 & 1.0 & $38-75$ & 0.2374 & 22.33 & 0.9991 & 1.4779 & 118.82 & 0.9947 & 1.1946 & 4.1259 & 0.9850 \\
\hline 160 & 40 & 1.0 & $38-75$ & 0.2240 & 31.05 & 0.9975 & 1.3989 & 123.77 & 0.9972 & 1.1410 & 4.1261 & 0.9890 \\
\hline 160 & 50 & 0.5 & $38-75$ & 0.1741 & 74.68 & 0.9997 & 1.0881 & 119.29 & 0.9997 & 0.6121 & 4.1074 & 0.9373 \\
\hline 160 & 50 & 1.5 & $38-75$ & 0.3861 & 25.26 & 0.9991 & 1.8734 & 133.92 & 0.9968 & 1.4006 & 4.2296 & 0.9381 \\
\hline 160 & 50 & 2.0 & $38-75$ & 0.4701 & 19.03 & 0.9975 & 2.2317 & 135.22 & 0.9680 & 1.5961 & 4.3701 & 0.9162 \\
\hline 160 & 50 & 1.0 & $38-54$ & 0.6774 & 36.43 & 0.9991 & 4.2221 & 116.63 & 0.9991 & 2.6983 & 3.6974 & 0.9751 \\
\hline 160 & 50 & 1.0 & $54-75$ & 0.2895 & 36.52 & 0.9992 & 1.7956 & 116.66 & 0.9989 & 1.0053 & 4.0673 & 0.9459 \\
\hline 160 & 50 & 1.0 & $75-100$ & 0.1480 & 36.14 & 0.9989 & 0.9251 & 116.28 & 0.9989 & 0.5123 & 4.5866 & 0.8942 \\
\hline
\end{tabular}

Notation: $C_{0}=$ initial concentration $(\mathrm{mg} / \mathrm{L}), m=$ weight $(\mathrm{mg}), Q=$ flow rate $(\mathrm{mL} / \mathrm{min}), \Phi=$ particle size $(\mathrm{mm}), k_{Y N}=$ Yoon-Nelson model rate constant, $\tau=$ the time required for $50 \%$ breakthrough $(\mathrm{min}), k_{\mathrm{Th}}=$ Thomas model rate constant $(\mathrm{mL} / \mathrm{mg} \mathrm{min}), q_{0}=$ equilibrium adsorption capacity $(\mathrm{mg} / \mathrm{g}), k_{\mathrm{AB}}=$ Adams-Bohart model rate constant $(\mathrm{L} / \mathrm{mg} \mathrm{min}), N_{0}=$ saturation concentration $(\mathrm{mg} / \mathrm{L})$.

effect on mass transfer. The breakthrough curves were obtained upon the changing of MIPs amount from 30 to $50 \mathrm{mg}$ as shown in Fig. S3.

\subsection{Breakthrough curve modeling}

\subsubsection{Yoon-Nelson model}

Yoon-Nelson model [44] is relatively simple comparing to other kinetic models. The model assumes that the decrease in the adsorption rate of the adsorbate is directly proportional to the adsorption rate of the adsorbate and the breakthrough of the adsorbate on the adsorbent, the formula is expressed as:

$\ln \left[\mathrm{C} /\left(\mathrm{C}_{0}-\mathrm{C}\right)\right]=k_{\mathrm{YN}} t-\tau k_{\mathrm{YN}}$

where $C_{0}(\mathrm{mg} / \mathrm{L})$ and $C(\mathrm{mg} / \mathrm{L})$ are initial concentrations of the solution and the effluent concentration after adsorption, $\mathrm{k}_{\mathrm{YN}}(1 / \mathrm{min})$ is the rate constant of Yoon-Nelson model, the $50 \%$ breakthrough is expressed by $\tau$ ( $\mathrm{min}$ ) and Yoon-Nelson model constant $\left(k_{\mathrm{YN}}\right)$, which were obtained from the linear relationship of $\ln \left[\mathrm{C} /\left(\mathrm{C}_{0}-\mathrm{C}\right)\right]$ against $t$. And the parameters calculated according to the model are presented in Table 2, where $k_{\mathrm{YN}}$ and $\tau k_{\mathrm{YN}}$ represent the slope and intercept (Fig. S4).

From Table 2, we can see that the rate constant $k_{\mathrm{YN}}$ increases and $\tau$ decreases with the increasing of influent concentration due to the fast saturation of the column at high adsorbate concentration. A similar trend was found on $k_{\mathrm{YN}}$ and $\tau$ in the case of increasing of the flow rate. This is due to the fact that a higher flow rate would result in the insufficient adsorption and early adsorption equilibrium. There is no significant change in the rate constant $k_{\mathrm{YN}}$ with an increase of 2, 4-D MIPs weight. Table 2 showed that determination coefficients $\left(R^{2}\right)$ values of the Yoon-Nelson model were higher than 0.99 at the given experimental conditions. The breakthrough curves were predicted according to the different parameters investigated in Fig. 8. It can be seen that the breakthrough curves predicted by Yoon-Nelson models are similar to the experimental breakthrough curves. Therefore, the adsorption behavior of 2, 4-D in MIPs column under different experimental conditions can be described very well by the Yoon-Nelson model.

\subsubsection{Thomas model}

H.C. Thomas proposed the Thomas model in 1944 [45]. It assumes that the adsorbate does not diffuse axially in the column. The model is expressed as:

$\ln \left(\mathrm{C}_{0} / \mathrm{C}-1\right)=\mathrm{k}_{\mathrm{Th}} \mathrm{q}_{0} \mathrm{~m} / \mathrm{Q}-\mathrm{k}_{\mathrm{Th}} \mathrm{C}_{0} \mathrm{t}$

where the initial concentration of the solution and effluent concentration at a time $t(\mathrm{~min})$ are expressed as $C_{0}(\mathrm{mg} / \mathrm{L})$ and $C(\mathrm{mg} / \mathrm{L})$, respectively. $k_{\mathrm{Th}}(\mathrm{mL} / \mathrm{min} \mathrm{mg})$ represents the Thomas model rate constant, $Q(\mathrm{~mL} / \mathrm{min})$ is the flow rate, $q_{0}(\mathrm{mg} / \mathrm{g})$ implies the equilibrium uptake capacity, $m(\mathrm{~g})$ is the amount of adsorbent in the column. The values of $k_{\mathrm{Th}}$ and $q_{0}$ can be obtained from the linear plot of $\ln \left(\mathrm{C}_{0} / \mathrm{C}-1\right)$ against time $(t)$, respectively. The values of $k_{\mathrm{Th}}$, $q_{0}$, and the correlation coefficient $\left(R^{2}\right)$ were obtained and listed in Table 2, where $\mathrm{k}_{\mathrm{Th}} \mathrm{C}_{0}$ and $\mathrm{k}_{\mathrm{Th}} \mathrm{q}_{0} \mathrm{~m} / \mathrm{Q}$ stand for slope and intercept (Fig. S5).

It can be clearly seen from Table 2 that $q_{0}$ value decreases and $k_{\mathrm{Th}}$ value increases as the flow rate increases. With increasing of 2,4-D concentration, $k_{\mathrm{Th}}$ value increases, whereas $q_{0}$ decreases. The reason is that the higher the 2,4-D concentration, the greater the driving force is. The value of $q_{0}$ and $k_{\text {Th }}$ did not significantly change with the increase of the MIPs mass. The value of $k_{\mathrm{Th}}$ decreases with the increase of particle size. It is found from Table 2 , 


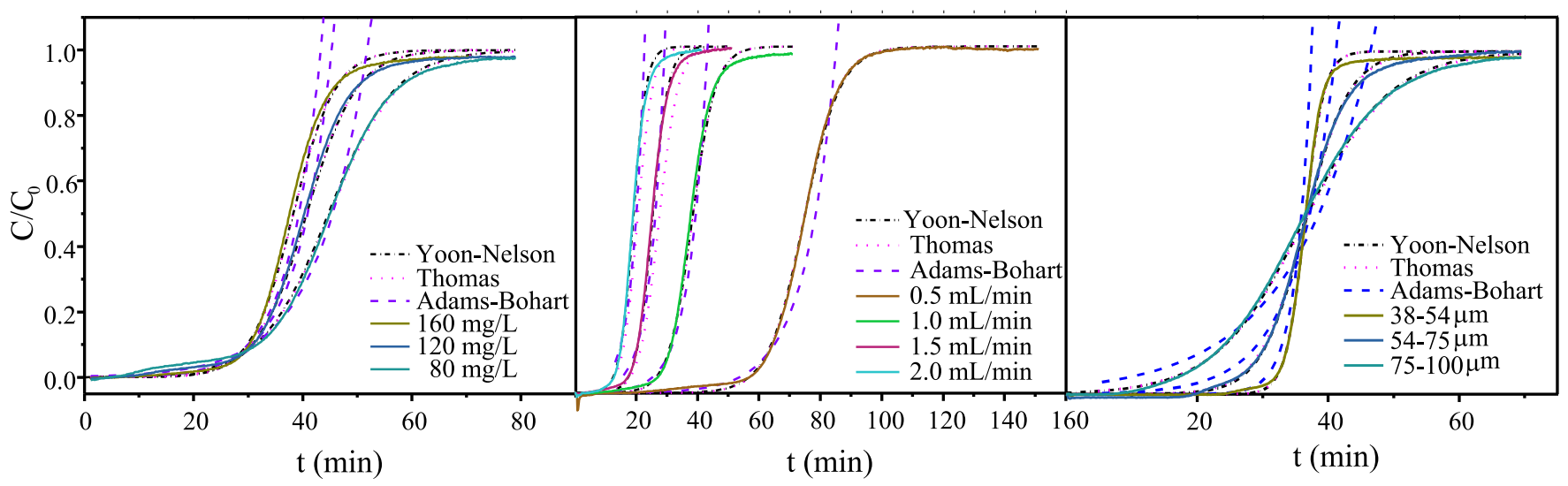

Fig. 8. Experimental and predicted breakthrough curves of 2,4-D on MIPs fixed-bed columns predicted by the Yoon-Nelson, Thomas and Adams-Bohart model.

the Thomas model correlation coefficients $\left(R^{2}\right)$ are between 0.9680 and 0.9997 . Fig. 8 shows the breakthrough curves obtained by the calculated parameters. It can be concluded that the Thomas model can fit the breakthrough curves well.

\subsubsection{Adams-Bohart model}

The Adams-Bohart model [46] is based on the hypothesis that adsorption equilibrium does not occur instantaneously. The equation is mainly used to describe the relationship between $C / C_{0}$ and $t$ in the fixed bed adsorption process. The initial part of the breakthrough curve is described by the Adams-Bohart model. The equation can be expressed as follows:

$\ln \left(\mathrm{C} / \mathrm{C}_{0}\right)=\mathrm{k}_{\mathrm{AB}} \mathrm{C}_{0} \mathrm{t}-\mathrm{k}_{\mathrm{AB}} \mathrm{N}_{0}(\mathrm{Z} / \mathrm{F})$

where $k_{\mathrm{AB}}(\mathrm{L} / \mathrm{mg} \min )$ is the rate constant, the initial concentration and concentration of effluent solution are represented as $C_{0}(\mathrm{mg} / \mathrm{L})$ and $C(\mathrm{mg} / \mathrm{L}) ; N_{0}(\mathrm{mg} / \mathrm{L})$ is saturation concentration; $Z(\mathrm{~cm})$ represents the height of adsorbent column; $F(\mathrm{~cm} / \mathrm{min})$ stands for the ratio of solution flow rate $Q$ to cross-sectional area $A$ of the column. From the linear plot of $\ln \left(\mathrm{C} / \mathrm{C}_{0}\right)$ against $t$, the parameters $k_{\mathrm{AB}}$ and $N_{0}$ in the model can be obtained, and the results are demonstrated in Table 2, where $\mathrm{k}_{\mathrm{AB}} \mathrm{C}_{0}$ and $\mathrm{k}_{\mathrm{AB}} \mathrm{N}_{0}(\mathrm{Z} / \mathrm{F})$ stand for slope and intercept, respectively (Fig. S6).

As illustrated in Table 2, the increase of 2,4-D concentration resulted in the decline of $k_{\mathrm{AB}}$ value, while the increase of $N_{0}$ value. With the increase of flow rate, $k_{\mathrm{AB}}$ increased, and $N_{0}$ decreased. The value of $k_{\mathrm{AB}}$ decreased with the increase of into the amount and size of particles. The correlation coefficients $\left(R^{2}\right)$ were fairly good as shown in Table 2. Additionally, the breakthrough curves (Fig. 8) predicted by the Adams-Bohart model did not match well with experimental curves. Thus, the Adams-Bohart model is not suitable for describing 2,4-D adsorption on MIPs fixed-bed column.

\subsection{Regeneration of 2, 4-D MIPS and NIPs}

When the column was completely saturated, the desorption experiment was performed with methanol at flow rates of 0.5 and $1.0 \mathrm{~mL} / \mathrm{min}$, respectively. The concentration of desorption effluent solution was calculated using the standard curve (Fig. S2(B)) established using the standard solutions prepared in methanol. It can be found from the curves in Fig. 9 that 2, 4-D could be completely desorbed within 2 min. Desorption rates were $96.37 \%$ and $99.88 \%$ at 0.5 and $1.0 \mathrm{~mL} / \mathrm{min}$, respectively.

Regeneration of used MIPs and NIPs were carried out with $50 \mathrm{~mL}$ methanol at a flow rate of $1.0 \mathrm{~mL} / \mathrm{min}$. The adsorption ability of the regenerated polymer particles was investigated by the on-line system.

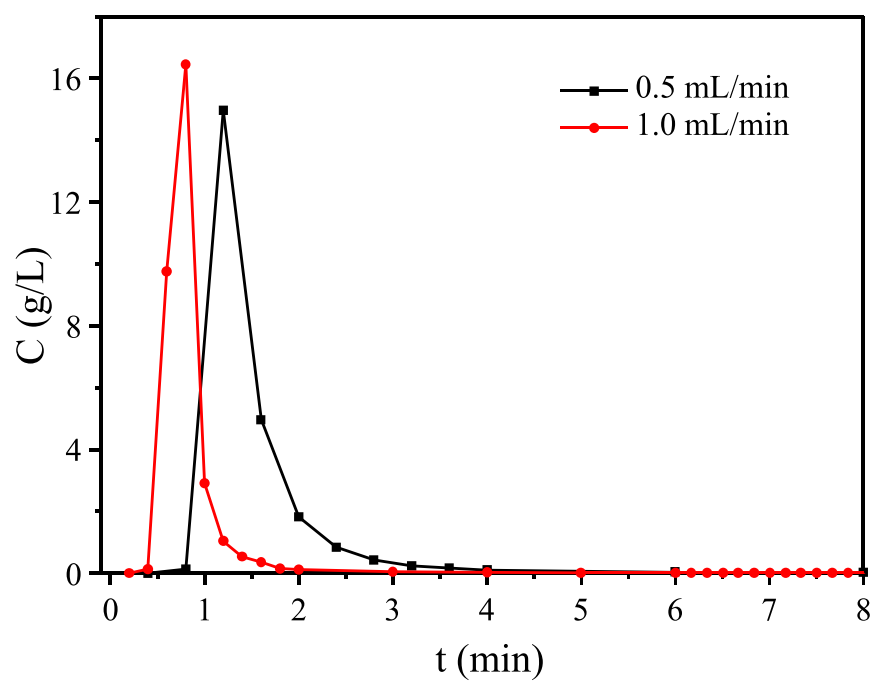

Fig. 9. Desorption kinetic curves at different flow rates.

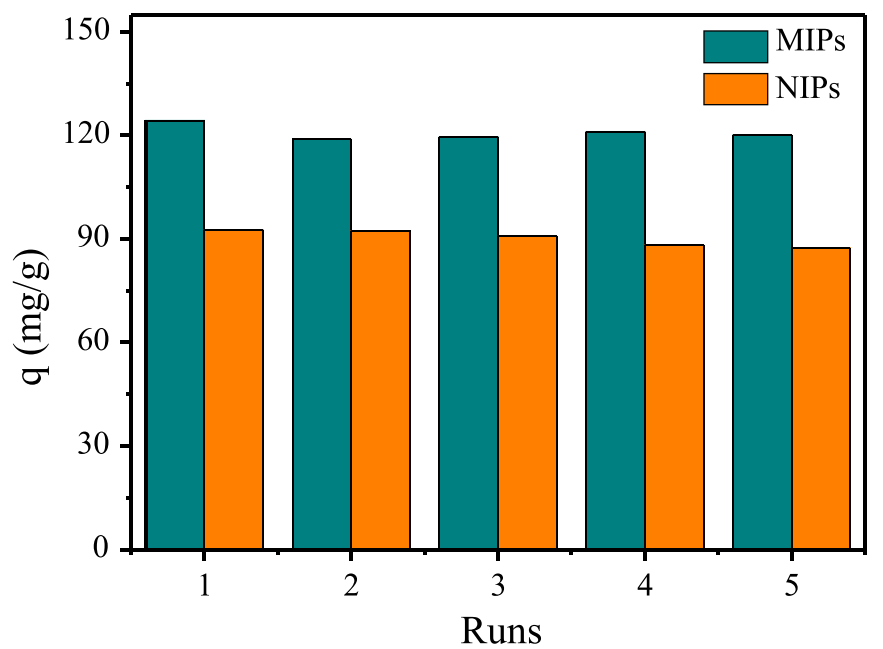

Fig. 10. Effect of polymers recycle times on 2,4-D adsorption capacity.

The regeneration of adsorbent is an effective means to reduce the cost. MIPs and NIPs can be reactivated due to the higher physical stability and chemical robustness than other materials $[47,48]$. In this study, the MIPs and NIPs were regenerated by extraction using methanol, as shown in Fig. 10. The results showed that the adsorption capacity of MIPs and NIPs did not change significantly 
after five reuses, indicating that they had outstanding repeatability. Therefore, the polymers are great potential adsorbents in the treatment of 2,4-D wastewater.

\subsection{Adsorption from real sample matrix}

In order to verify the applicability of the material on the real water sample, the lake water was tested. As there was no detectable amount of 2,4-D found in the sample, the water was spiked at $20 \mathrm{mg} / \mathrm{L}$ and used for the fixed bed adsorption. As shown in Fig. S7, the breakthrough curve was obtained with a smooth Sshape. Furthermore, the curve shows that the breakthrough time is $40.51 \mathrm{~min}$, the exhaustion time is $92.16 \mathrm{~min}$ and the adsorption capacity is $28.50 \mathrm{mg} / \mathrm{g}$. Therefore, the method is valid for the measurement of real sample adsorption.

\section{Conclusions}

In this paper, a novel method based on the self-assembled FOS system was investigated to determine the adsorption kinetics of 2,4-D MIPs in fixed bed mode. This investigation confirmed that on-line, automatic, precise measurement of adsorption kinetics can be achieved by the system. The measurement results showed that adsorption kinetics of the imprinted polymers fit to Thomas and Yoon-Nelson models. And the polymers showed to have high binding capacity, good selectivity, fast adsorption rate, indicating a great potential in the treatment of 2,4-D wastewater. The FOS system being on-line, realtime, simple and reproducible can overcome the limitations of traditional sampling method in the detection of the fixed bed adsorption kinetics. In addition, the system can collect much greater data at a given time interval than traditional methods. And further work needs to be done to explore applications of the system in the kinetic measurement of a single adsorbate in wastewater and multicomponent adsorption.

\section{Credit author statement}

Turghun Muhammad: Conceptualization, Methodology, Supervision, Writing- Reviewing and Editing. Yiting Hu: Data curation, Writing- Original draft preparation, Investigation. Beibei Wu: Software, Validation. Aixia Wei: Formal analysis. Xiaoxia Yang: Validation. Lingxin Chen: Writing- Reviewing and Editing.

\section{Declaration of Competing Interest}

The authors declare that they have no known competing financial interests or personal relationships that could have appeared to influence the work reported in this paper.

\section{Acknowledgments}

This work was supported by the National Natural Science Foundation of China (21565025), State Key Laboratory of Chemo/Biosensing and Chemometrics (2018013), the Department of Science and Technology of Shandong Province of China (GG201709290055; 2017ZH093) and Taishan Scholar Project Special Funding (ts20190962).

\section{Supplementary materials}

Supplementary material associated with this article can be found, in the online version, at doi:10.1016/j.chroma.2020.461112.

\section{References}

[1] L. Ding, X. Lu, H.P. Deng, X.X. Zhang, Adsorptive removal of 2,4Dichlorophenoxyacetic acid (2,4-D) from aqueous solutions using MIEX resin, Ind. Eng. Chem. Res. 51 (2012) 11226-11235 https://doi.org/10.1021/ie300469h.

[2] B.H. Hameed, J.M. Salman, A.L. Ahmad, Adsorption isotherm and kinetic modeling of 2,4-D pesticide on activated carbon derived from date stones, J. Hazard. Mater. 163 (2009) 121-126 https://doi.org/10.1016/j.jhazmat.2008. 06.069.

[3] J. Goscianska, A. Olejnik, Removal of 2,4-D herbicide from aqueous solution by aminosilane-grafted mesoporous carbons, Adsorption 25 (2019) 345-355 https://doi.org/10.1007/s10450-019-00015-7.

[4] Y.L. Liu, Y.H. He, Y.L. Jin, Y.Y. Huang, G.Q. Liu, R. Zhao, Preparation of monodispersed macroporous core-shell molecularly imprinted particles and their application in the determination of 2,4-dichlorophenoxyacetic acid, J. Chromatogr. A 1323 (2014) 11-17 https://doi.org/10.1016/j.chroma.2013.11.002.

[5] D.M. Han, W.P. Jia, H.D. Liang, Selective removal of 2,4-dichlorophenoxyacetic acid from water by molecularly-imprinted amino-functionalized silica gel sorbent, J. Environ. Sci. 22 (2010) 237-241 https://doi.org/10.1016/s1001-0742(09) 60099-1.

[6] Ministry of Health of China, China national standardization management committee, National standard of PRC: "Standard for Drinking Water Quality", City Town Water Supply 4 (2007) 27-31 https://doi.org/CNKI:SUN:CZGS.0.2007-04-009.

[7] B. Tang, J. Zhang, N.J. Yang, G.H. Zhao, Selective photoelectrocatalytic removal of environmental pollutants on molecular imprints decorated $\mathrm{TiO}_{2}$ single crystalline nanoarrays, Chem. Eng. J. (2019) https://doi.org/10.1016/j.cej. 2019.123188.

[8] J.Y. Gu, H. Chen, F. Jiang, X. Wang, L.Y. Li, All-solid-state Z-scheme Co9S8/graphitic carbon nitride photocatalysts for simultaneous reduction of $\mathrm{Cr}(\mathrm{VI})$ and oxidation of 2,4-dichlorophenoxyacetic acid under simulated solar irradiation, Chem. Eng. J. 360 (2019) 1188-1198 https://doi.org/10.1016/j.cej. 2018.10.137.

[9] H. Chen, Z.L. Zhang, Z.L. Yang, Q. Yang, B. Li, Z.Y. Bai, Heterogeneous fentonlike catalytic degradation of 2,4-dichlorophenoxyacetic acid in water with $\mathrm{FeS}$, Chem. Eng. J. 273 (2015) 481-489 https://doi.org/10.1016/j.cej.2015.03.079.

[10] R.C. Li, X.Y. Jin, M. Megharaj, R. Naidu, Z.L. Chen, Heterogeneous Fenton oxidation of 2,4-dichlorophenol using iron-based nanoparticles and persulfate system, Chem. Eng. J. 264 (2015) 587-594 https://doi.org/10.1016/j.cej.2014.11.128.

[11] T. Zhou, T.T. Lim, S.S. Chin, A.G. Fane, Treatment of organics in reverse osmosis concentrate from a municipal wastewater reclamation plant: feasibility test of advanced oxidation processes with/without pretreatment, Chem. Eng. J. 166 (2011) 932-939 https://doi.org/10.1016/j.cej.2010.11.078.

[12] N. Jaafarzadeh, F. Ghanbari, M. Ahmadi, Efficient degradation of 2,4dichlorophenoxyacetic acid by peroxymonosulfate/magnetic copper ferrite nanoparticles/ozone: a novel combination of advanced oxidation processes, Chem. Eng. J. 320 (2017) 436-447 https://doi.org/10.1016/j.cej.2017.03.036.

[13] B. Tang, H.J. Shi, Z.Y. Fan, G.H. Zhao, Preferential electrocatalytic degradation of 2,4-dichlorophenoxyacetic acid on molecular imprinted mesoporous $\mathrm{SnO}_{2}$ surface, Chem. Eng. J. 334 (2018) 882-890 https://doi.org/10.1016/j.cej.2017.10. 086.

[14] L.J. Banasiak, B. Van der Bruggen, A.I. Schäfer, Sorption of pesticide endosulfan by electrodialysis membranes, Chem. Eng. J. 166 (2011) 233-239 https://doi. org/10.1016/j.cej.2010.10.066.

[15] Z. Aksu, E. Kabasakal, Batch adsorption of 2,4-dichlorophenoxy-acetic acid (2,4D) from aqueous solution by granular activated carbon, Sep. Purif. Technol. 35 (2004) 223-240 https://doi.org/10.1016/s1383-5866(03)00144-8.

[16] F.M. de Souza, O.A. Andreo dos Santos, M.G. Adeodato Vieira, Adsorption of herbicide 2,4-D from aqueous solution using organo-modified bentonite clay, Environ. Sci. Pollut. Res. 26 (2019) 18329-18342 https://doi.org/10.1007/ s11356-019-05196-w.

[17] J.M. Salman, V.O. Njoku, B.H. Hameed, Batch and fixed-bed adsorption of 2,4dichlorophenoxyacetic acid onto oil palm frond activated carbon, Chem. Eng. J. 174 (2011) 33-40 https://doi.org/10.1016/j.cej.2011.08.024.

[18] V.O. Njoku, M. Asif, B.H. Hameed, 2,4-Dichlorophenoxyacetic acid adsorption onto coconut shell-activated carbon: isotherm and kinetic modeling, Desalin. Water Treat. 55 (2014) 132-141 https://doi.org/10.1080/19443994.2014.911708.

[19] B.K. Jung, Z. Hasan, S.H. Jhung, Adsorptive removal of 2,4dichlorophenoxyacetic acid (2,4-D) from water with a metal-organic framework, Chem. Eng. J. 234 (2013) 99-105 https://doi.org/10.1016/j.cej.2013.08.110.

[20] K. Haupt, A. Dzgoev, K. Mosbach, Assay system for the herbicide 2,4dichlorophenoxyacetic acid using a molecularly imprinted polymer as an artificial recognition element, Anal. Chem. 70 (1998) 628-631 https://doi.org/10. 1021/ac9711549.

[21] S. Koner, A. Pal, A. Adak, Adsorption of 2,4-D herbicide from water environment on modified silica gel factory waste, Water Environ. Res. 85 (2013) 2147 2156 https://doi.org/10.2175/106143013X13736496909310.

[22] A. Olejnik, I. Nowak, G. Schroeder, Functionalized polystyrene beads as carriers in release studies of two herbicides: 2,4-dichlorophenoxyacetic acid and 2-methyl-4-chlorophenoxyacetic acid, Int. J. Environ. Sci. Technol. 16 (2018) 5623-5634 https://doi.org/10.1007/s13762-018-2138-4.

[23] S.J. Chen, J.X. Fu, Z.W. Li, Y. Zeng, Y.Z. Li, X. Su, X.L. Jiang, H. Yang, L. Huang L.K. Zou, L. He, S.L. Liu, X.L. Ao, Y. Yang, Preparation and application of magnetic molecular imprinted polymers for extraction of cephalexin from pork and milk samples, J. Chromatogr. A 1602 (2019) 124-134 https://doi.org/10.1016/j. chroma.2019.06.032. 
[24] S. Singh, V.C. Srivastava, I.D. Mall, Fixed-bed study for adsorptive removal of furfural by activated carbon, Colloids Surf. A 332 (2009) 50-56 https://doi.org/ 10.1016/j.colsurfa.2008.08.025.

[25] C.M. Futalan, C.C. Kan, M.L. Dalida, C. Pascua, M.W. Wan, Fixed-bed column studies on the removal of copper using chitosan immobilized on bentonite, Carbohydr. Polym. 83 (2011) 697-704 https://doi.org/10.1016/j.carbpol.2010.08. 043.

[26] M.J. Meng, M. Zhang, Y. Liu, Y.J. Ji, J. Wang, Y. Wu, Y. Yan, Highly efficient adsorption of salicylic acid from aqueous solution by wollastonite-based imprinted adsorbent: a fixed-bed column study, Chem. Eng. J. 225 (2013) 331339 https://doi.org/10.1016/j.cej.2013.03.080.

[27] Y. Qiu, F.S. Zhang, F.Q. Zhao, X.Q. Song, Multichannel chemiluminescence detector based on the charge coupled device and optical fibre technology, Instrum. Sci. Technol. 23 (1995) 49-55 https://doi.org/10.1080/10739149508011696.

[28] O.S. Wolfbeis, Fiber-optic chemical sensors and biosensors, Anal. Chem. 74 (2002) 2663-2678 https://doi.org/10.1021/acs.analchem.5b04298.

[29] A. Guillot, M. Limberger, J. Krämer, C.-M. Lehr, In stu drug release monitoring with a fiber-optic system: overcoming matrix interferences using derivative spectrophotometry, Dissolut. Technol. 20 (2013) 15-19 https://doi.org/10. 14227/dt200213p15.

[30] J. Buerck, S. Roth, K. Kraemer, M. Scholz, N. Klaas, Application of a fiber-optic NIR-EFA sensor system for in situ monitoring of aromatic hydrocarbons in contaminated groundwater., J. Hazard. Mater. 83 (2001) 11-28 https://doi.org/10. 1016/S0304-3894(00)00335-6.

[31] H.B. Zhang, W.J. Xiao, D.S. Zhao, Y. Liu, S.C. Hu, C.L. Chen, P.P. Xu, X.X. Li, J. Chen, Fiber-optic in situ analysis of the catalytic kinetics of the alliin/alliinase system, J. Mol. Catal. B 106 (2014) 111-116 https://doi.org/10.1016/j.molcatb. 2014.05.006.

[32] F. Gao, T. Muhammad, M. Bakri, W.W. Yang, P. Parezhati, X.X. Yang, In-situ measurement of the adsorption thermodynamics of rutin on macroporous adsorption resins by fiber-optic sensing, Instrum. Sci. Technol. 47 (2018) 170-184 https://doi.org/10.1080/10739149.2018.1505636.

[33] F. Gao, T. Muhammad, M. Bakri, P. Parezhati, L.X. Chen, In situ liquid-phaseadsorption measurement system based on fiber-optic sensing with the aid of membranes, ACS Omega 3 (2018) 10891-10897 https://doi.org/10.1021/ acsomega.8b01059.

[34] M. Karimi, A. Shojaei, A. Nematollahzadeh, M.J. Abdekhodaie, Column study of $\mathrm{Cr}$ (VI) adsorption onto modified silica-polyacrylamide microspheres composite, Chem. Eng. J. 210 (2012) 280-288 https://doi.org/10.1016/j.cej.2012.08.046.

[35] C. Baggiani, C. Giovannoli, L. Anfossi, C. Passini, P. Baravalle, G. Giraudi, A connection between the binding properties of imprinted and nonimprinted polymers: a change of perspective in molecular imprinting, J. Am. Chem. Soc. 134 (2012) 1513-1518 https://doi.org/10.1021/ja205632t.

[36] T. Muhammad, C. Liu, J.D. Wang, E.V. Piletska, A.R. Guerreiro, S.A. Piletsky, Rational design and synthesis of water-compatible molecularly imprinted polymers for selective solid phase extraction of amiodarone, Anal. Chim. Acta. 709 (2012) 98-104 https://doi.org/10.1016/j.aca.2011.10.009.
[37] I. Kavianinia, P.G. Plieger, N.G. Kandile, D.R.K. Harding, Fixed-bed column studies on a modified chitosan hydrogel for detoxification of aqueous solutions from copper (II), Carbohydr. Polym. 90 (2012) 875-886 https://doi.org/10.1016/ j.carbpol.2012.06.014

[38] K.H. Chu, Fixed bed sorption: setting the record straight on the Bohart-Adams and Thomas models, J. Hazard. Mater. 177 (2010) 1006-1012 https://doi.org/10. 1016/j.jhazmat.2010.01.019.

[39] Y.H. Zhang, F. Jin, Z.T. Shen, F. Wang, R. Lynch, A. Al-Tabbaa, Adsorption of methyl tert-butyl ether (MTBE) onto ZSM-5 zeolite: fixed-bed column tests, breakthrough curve modelling and regeneration, Chemosphere 220 (2019) 422-431 https://doi.org/10.1016/j.chemosphere.2018.12.170.

[40] W.X. Zhang, L. Dong, H. Yan, H.J. Li, Z.W. Jiang, X.W. Kan, H. Yang, A.M. Li, R.S. Cheng, Removal of methylene blue from aqueous solutions by straw based adsorbent in a fixed-bed column, Chem. Eng. J. 173 (2011) 429-436 https:// doi.org/10.1016/j.cej.2011.08.001.

[41] S.Y. Quek, B. Al-Duri, Application of film-pore diffusion model for the adsorption of metal ions on coir in a fixed-bed column, Chem. Eng. Process. 46 (2007) 477-485 https://doi.org/10.1016/j.cep.2006.06.019.

[42] X.G. Luo, J. Yuan, Y.G. Liu, C. Liu, X.R. Zhu, X.H. Dai, Z.C. Ma, F. Wang, Improved solid-phase synthesis of phosphorylated cellulose microsphere adsorbents for highly effective $\mathrm{Pb} 2+$ removal from water-batch and fixed-bed column performance and adsorption mechanism, ACS Sustain. Chem. Eng. 5 (2017) 51085117 https://doi.org/10.1021/acssuschemeng.7b00472.

[43] L. Lv, K. Wang, X.S. Zhao, Effect of operating conditions on the removal of $\mathrm{Pb} 2+$ by microporous titanosilicate ETS-10 in a fixed-bed column, J. Colloid Interface Sci. 305 (2007) 218-225 https://doi.org/10.1016/j.jcis.2006.09.053.

[44] Y.H. Yoon, J.H. Nelson, Application of gas adsorption kinetics-II. A theoretical model for respirator cartridge service life and its practical applications, Am. Ind. Hyg. Assoc. J. 45 (1984) 517-524 https://doi.org/10.1080/ 15298668491400205.

[45] H.C. Thomas, Heterogeneous ion exchange in a flowing system, J. Am. Chem Soc. 66 (1944) 1664-1666 https://doi.org/10.1021/ja01238a017.

[46] G.S. Bohart, E.Q. Adams, Some aspects of the behavior of charcoal with respect to chlorine, J. Am. Chem. Soc. 42 (1920) 523-554 https://doi.org/10.1016/ S0016-0032(20)90400-3.

[47] C.M. Dai, S.U. Geissen, Y.L. Zhang, Y.J. Zhang, X.F. Zhou, Performance evaluation and application of molecularly imprinted polymer for separation of carbamazepine in aqueous solution, J. Hazard. Mater. 184 (2010) 156-163 https: //doi.org/10.1016/j.jhazmat.2010.08.018.

[48] N.M. Maier, G. Buttinger, S. Welhartizki, E. Gavioli, W. Lindner, Molecularly imprinted polymer-assisted sample clean-up of ochratoxin A from red wine: merits and limitations, J. Chromatogr. B 804 (2004) 103-111 https://doi.org/10. 1016/j.jchromb.2004.01.014. 